\title{
The Relation Between Conversational Strategies Used in Hard News Interview to the Roles of Being a Particular Institutional Representative: An Analysis
}

\author{
Nik Ahmad Farhan Azim @ Nik Azim \\ Centre for Language Studies and Generic Development, Universiti Malaysia Kelantan, \\ Kelantan, Malaysia \\ E-mail address: farhan.na@umk.edu.my
}

\begin{abstract}
Keywords: Turn-taking organization, adjacency relationship, transition relevance places,
\end{abstract} conversation analysis

\begin{abstract}
A normal conversation often follows a single transition in which adjacency pair demands co-related and immediate feedback. However, when this synergy is violated to some extent, it is believed that this will lead to unequal turn-taking especially in institutional dialogue. Different social settings could also allow some conversational participants to be dominant or less dominant. This study will investigate the effect of institutional role by using some of the strategy proposed by Heritage. Heritage asserts that these four strategies that will be discussed in this paper namely turn-taking organization, turn design organization, sequence organization and repair organization, enables researcher to determine the institutional field or roles of any speaker in a conversation. Other factor such as lexical choices, which may likely to be associated with the speaker's institutional representation will also be analyzed.
\end{abstract}

\section{INTRODUCTION}

A conversation between two speakers are locally managed and internationally controlled [6]. Thornborrow further asserts that the participants in conversation are expected to have different turntaking that will affect their institutional roles [10]. A normal conversation often follows a single transition at a time; which is one speaker speaking at a time while the other listens. The hearer, on the other hand may give appropriate feedback to the speaker. This is how adjacency relationship works. The utterances between the adjacent pairs demand co-related and immediate feedback. These are the focal element in building up the structure organization of any conversation. Thus, provides a referral point to each speaker [8]. Goodwin mentioned that one of the many adjacent turns in conversation take the form of question-answer [3]. This happens in many news interviews where there are mainly two institutional representatives with different roles in the interaction.

In a single conversation, only one person is permitted to talk at each time [8]. This occurs in a series of a "fundamentally a sequential activity" where participants in a conversation mutually construct a pattern of turn-taking [5]. In a question-answer conversation, Goffman points out that a question sets up expectations of a response and the response is then made within the constraints of these expectations [12]. In other words, the response from the interviewee is being conditioned by the interviewer's question. Thus, the interviewee is supposed to give his comments or remarks within the conditioned expectations. Certainly, adjacency pairs are pervasive element in conversation and by predicting a response from the other participant, the second pair part is thereby constrained and is expected to cohere with the first pair part [12]. Such situation is important in organization of turn-taking system because the first pair part set up "transition relevance places" or TRPs and also act to constrain both the next utterances and the next speaker [7]. However, this could sometimes lead to some problem where transition point of each speaker is hard to be determined [8]. Such interruption could violate the whole conversation.

On the other hand, Sacks agrees that interruptions can occur during conversations [8]. Overlapping and interruptions can occur when the speaker need to request for clarification, completing and restating or complementing other speaker's statement [2]. Warren mentioned that in 
the case of an overlap, one of the participants yields the floor quite quickly [12]. More often than not, the person who begins to speak last is the one to yield the floor. Sacks et al. mention that a person who interrupts a speaker and is found to be speaking at the same time has frequently begun his contribution at a TRP but the previous speaker does not finish, creating an overlap conversation [7].

Apart from that, another feature such as sequencing can also be analyzed in media talk. Norsfinger regards adjacencies or turn-taking in conversation as a "fundamentally sequential activity" rather than a set of rules that need to be followed [5]. Furthermore, turn-takings or adjacency is "locally occasioned" [11]. However, Cheepan notes that there is an unequal turn-taking in an institutional dialogues [1]. This is due to different social settings that allow some participants to be dominant, while at the same time, restricting other's opportunity to moves in. In addition, Thornborrow founds that only interviewer has the chance to maneuver the direction and set the topic of the discussion [10].

Therefore, this study is aiming to investigate the effect of institutional role by using some of the strategy proposed by Heritage [4]. Heritage asserts that these four strategies that will be discussed in this paper namely turn-taking organization, turn design organization, sequence organization and repair organization, enables researcher to determine the institutional field or roles of any speaker in a conversation. Other factor such as lexical choices, which may likely to be associated with the speaker's institutional representation will also be analyzed.

\section{METHODOLOGY}

Warre asserts that conversation analysis (CA) is more interested in interaction exemplifying social order and consciously avoids the creation of any interaction models [12]. Instead, concentration is being given on conversation structure, namely the small-scale features of conversational organization, such as turn-taking systems and view adjacency pairs as the basic unit of interaction. Therefore, in this qualitative research, it is found that there is not much theoretical framework that needs to be adhered since CA is mainly emphasized on the questioning and further clarifying theories that are used before, as further supported by Ten Have [9].

The interview of this research was a television news interview where there are one interviewer and one interviewee. It was obtained from a reputable American news network's website with secretarial transcription of the interview is readily available. There are some minor spelling mistakes in this transcription which are then corrected appropriately based on thirteen minutes recording. The transcription is then being analyzed into a fuller CA transcription by relistened to the online video many times. In completing CA transcription, a set of transcription symbols are being used:

\subsection{Conversation Analysis Transcription Symbols}

(.5) The number in brackets indicates a time gap in tenths of a second.

(.) A dot enclosed in a et indicates pause in the talk less than two tenths of a second

[ ] Indicates an overlap

[[ A double left-band bracket indicates that speakers start a turn simultaneously.

$><\quad$ 'More than' and 'les than' indicate that the talk they encompass was produced noticeably $>$ quicker $<$ than the surrounding talk

$\uparrow \quad$ Indicates a rising tone

$\downarrow \quad$ Indicates a falling tone

Indicates stress words or syllables

$\overline{(())}$ A description enclosed in a double bracket indicates a non-verbal activity, for example ((banging sound)).

$=\quad$ The equals sign indicates contiguous utterances

- $\quad$ A dash indicates the sharp cut-off of the prior word or sound

: $\quad$ Colon indicates that the speaker has stretched the preceding sound or letter. 
There are four important elements that will be discussed in this research namely turn-taking organization, turn design organization, sequence organization and repair organization. Other factor such as choices of lexical item will also be discussed as a minor element.

\section{DATA ANALYSIS}

\subsection{Turn-taking Organization}

Turn-taking organization is clearly dominated by the interviewee (Trump). This can be seen when Trump decided to address the interviewer's name (Larry) when answering a question or making some remark about his comment. The strategy used by the interviewee is interesting because the responses from the interviewee are exclusive for the interviewer and not for the general audience. The reasons of the interviewee doing this action will only be discussed in the discussion part. The interviewee selections can be seen in five instances during the interview as demonstrated in Excerpt 3.1.1.

\section{Excerpt 3.1.1}

(a) 9. DT: Well, I'm having a lot of fun, Larry $\downarrow$

(b) 39. DT: It's very therapeutic, Larry(.)

(c) 52. DT: [ [I know you - hey, Larry, I've know you for a long time and you carry it, all right?

(d)178. =People are incentivized(.) But you also look at certain things like

179. subprime and Larry $>$ I'm not blaming him for subprime $<$ I'm blaming him

180. for a war(.)

(e) 230. making unbelieveable deals on real estate(.) [[And one other thing,

\section{$\operatorname{Larry}($.}

231. you read all the about subprime and all about the people (hhh)(.) I don't

232. understand where these people come from(.)

(The bolds fonts in lines 9, 39, 52,179 and 230 are indications of interviewee addressing the interviewer by his name.)

However, interruptions and overlaps can be detected throughout the interview in spite of good selection process made by the speaker. For instance, in Excerpt 3.1.2 (a), and (b) overlaps occur when interviewer interjecting to the discussion as he detected potential TRP made by the interviewer. This happened when the interviewer immediately respond to the important points made by the interviewee. There is also another part of interruption where the interviewer was interrupted by the question posed by the interviewee. It is an interesting that the interviewee poses a question to the interviewer to possibly demonstrate his uncertainty about the statement from Rosie O'Donnell's book read by the interviewer. This can be seen in Excerpt 3.1.2 (c).

\section{Excerpt 3.1.2 (a)}

44. LK: You were that way $\uparrow$ in school $\downarrow$ as a kid?

45. DT: [I think so (.)].

(Pauses that are possibly interpreted as a TRP by the interviewer)

46. LK: [You got $\uparrow$ even $\uparrow ?]$ - tries to pose a question, thus overlap with DT

47. DT: I think get even $\downarrow$ I think get even $\downarrow$ Don’t you $\uparrow$ ?

\section{Excerpt 3.1.2 (b)}

60. DT: Yes=She got on a show(.2) and started saying(.) you know, she

61. started a rant:: 
62. LK: [[[On “The View" $\uparrow]$

63. DT: On "The View"=And she started ranting and raving about me(.) And

64. it was like::

65. LK: [[[Oh, when you forgave me that: winner of the contest, yes.]

(An interruption as indication to conform the statement known possibly only by the interviewer and audience who follow the issue of Donald Trump versus Rosie O'Donnell.)

Excerpt 3.1.2 (c)

115. LK: In her new book, she devotes a whole chapter, about 13 pages, to the

116. verbal smackdown she(.) the two of you had-In a chapter she titled

117. "Trumped, $\uparrow$ she talks about how she kept Trump brand cologne, vodka and

118. a bobblehead doll in her home office(.) She writes: "I kept"

119. DT: [I wonder what she did with it].

120. LK: [["I kept Trump products in my office because they reminded me that

121. my attacker was not a human being, but a wind up toy(.) with Tourette

122. Syndrome(.) a man who had allows himself to get pulled so deeply into

123. capitalism(.) that he turn his entire being into a product with a price tag on

124. it(.) He was gift-wrapped and stuffed with Styrofoam".

(An interruption as indication to conform and show interviewee's uncertainty about the phrases in the book)

\subsection{Turn Design Organization}

In this interview, the turn design organization is framed in away that formality of the conversation can be seen as less formal in spite of some degree of formality being normally associated with hard news interview. It is interesting to note that although most questions are set on less formal situation, the interviewee employ different pattern in answering the question. He starts by giving his personal point of view and gradually develops the answers by including his organization's point of view. This situation is demonstrated in Excerpt 3.2.1.

\section{Excerpt 3.2.1}

16. DT: Well, maybe for some people=But for me, this sort of(.2) I've had a

17. good time(.) Hopefully, I'll always have a good time(.) but we've-we've

18. really—we've done well and I'm happy about it.

i) "me" refers to the interviewee, Donald Trump

ii) "we" refers to the employees of Trump Group of Companies

\subsection{Sequence Organization}

Sequence organization in this interview follows the basic question and answer cycle. It can be seen that almost every question from the interviewer being answered by the interviewee consistently. The interviewer has also posed a question based on information that he obtained from the interviewee's respond previously. Thus, producing a logical anaphoric referencing strategy. This strategy enables the interview to be done in a logical and coherent way. This can be seen in Excerpt 3.3.1. 


\section{Excerpt 3.3.1}

20. DT: The group came to me at The Learning Annex, which is a great

21. institution(.2) They asked me to do a book-a book on toughness, on

22. making money, on sort of creating a happy life, in a certain sense, through

23. money and through other things(.2) And we came up with the title, which I

24. think is pretty descriptive, although some people thought it was a little bit

25. tough, adding the words "kick ass"'(.) but its is a little bit about kicking ass

26. because, unfortunately in life, sometimes you have to do that(.) And(.) the

27. book has become a tremendous best-seller $\uparrow$.

28. LK: Already?

29. DT: [Yes, well] it's not out yet and it's already gone to number one on the

30. charts(.) And 675,000 books have already been ordered(.2) So it's been

31. an amazing thing.

32. LK: is this your method or what you're saying should be everybody's

33. method?

(The word I bold in line 26 and 27 is an instance of anaphoric reference from later question posed by the interviewer. The word "method" in the question posed by the interviewer refers to the "kicking ass method" as described in line 26 and 27.)

During the interview, the interviewer can be seen to repeat his question for the purpose of producing more coherent answers by the interviewee. Thus, enables the organization of the interview to be more coherent and consistent. This can be seen in Excerpt 3.3.2. It is also found that the interviewer uses different style when repeatedly asking the question while at the same time, maintain the direction of the question.

\section{Excerpt 3.3.2}

191. LK: Is the religion rap on Romney a bad $\uparrow$ one $\uparrow$ ?

192. DT: I don't think it's a bad one=I think that it's - look, he's - he's a great

193. $\operatorname{person}($.$) And [you have]$

194. LK: You don't think it's a bad rap or you think it's a bad rap?

195. DT: No, don't think it's a-I don't think it's a bad rap(.) I don't think it's

196. going to have that much of an impact, ultimately.

197. LK: You don't $\uparrow$ ?

198. DT: I don't think $\underline{\text { so }} \downarrow$ No, I don't think $\underline{\text { so }} \downarrow$

(Italicized and bold font in lines 191, 193 and 197 are instance of repeated question. Note that there are differences of questioning style by the interviewer.)

\subsection{Repair Organization}

Repair occurs when there are interferences during a conversation. The interferences can be in form of phonological or morphological misuse at linguistic level or misunderstanding or denying other's speaker's turn to speak. These interferences are tolerated in most cases. In this interview, there are no repair activity can be detected. Most of the time, either the interviewer or the interviewee does not realizes the need of repairing when overlaps occurred. This can be seen in Excerpt 3.4.1. 


\section{Excerpt 3.4.1}

48. LK: Yes, you like it(.) But I don't like to carry it, though: If it carries too

49. much it's::

50. DT: You like to carry it.

51. LK: [All right].

52. DT: I[I know you-hey, Larry, I've know you for a long time and you carry

53. it, all right?

54. LK: [[[Let's talk about:: (.2)]

55. DT: People don't know that about you, but I do.

56. LK: Let's talk what one revenge aspect you talk about in the book, your

57. feud with Rosie O’Donnell(.) Who $\uparrow$ started that, by the way $\downarrow$ ?

(Italicized and bold sentences in lines 50, 52, 53 and 55 are indications of the interviewee interrupting without apology.)

\subsection{Other Data}

The choices of words used in the interview are hardly influenced by their respective institutions. There are instances in the interview where words such as "money, "subprime", "investment", "deals", "real estate", "tax incentives", "price", "interest" and "bank" are used. This reflects the institution where the interviewee came from and established. On the other hand, he responded over the Iraq war issue with different choice of lexical items. Words such as "military", "weapons of mass destruction", "terrorists" and "war" dominated that part of the interview as demonstrated in Excerpt 3.5.1 (a) and (b) respectively.

\section{Excerpt 3.5.1 (a)}

\section{Example 1}

228. terrible(.) absolutely terrible(.) But(.) this is the time=You were talking

229. about books(.) This is the time(.) that people should be going out and

230. making unbelieveable deals on real estate(.) [[And one other thing, Larry(.)

231. you read all the about subprime and all about the people (hhh)(.) I don't

232. understand where these people come from(.) The bank sends them a

233. letter $\downarrow$ (.) and they leave $\uparrow($.$) They send them a letter \downarrow$ you should be out(.)

234. They leave $\downarrow$ Why don't they call up the bank and negotiate $\uparrow$ ?

\section{Example 2}

235. DT: The bank doesn't want to take over their house $\uparrow(($ smiley voice $))(.2)$ I

236. mean, the bank $\uparrow$ whether they are nice or not(.) You can make a better

237. deal than you would have made five years ago with the bank(.) Cut the

238. $\underline{\text { price }} \uparrow \uparrow$ make it interest $\uparrow$ make it long-term $\uparrow($.$) The bank needs these$

239. people(.) But what happens is the bank sends them a notice, the people

240. leave $\uparrow($.$) I don't get it \uparrow$.

(Bold and italicized fonts in lines 230, 231, 234, 235, 236 and 237 indicates the register used by the interviewee when commenting on the real estate issue.)

\section{Excerpt 3.5.1 (b)}

152. DT: Well, I just hate what's happened to this country(.) We've gone to a

153. country that'a no longer respected(.) We're in a war that we should have

154. never--> and by the way< I'm worse than any hawk there is in terms of 
155. military and in terms of defending ourselves(.) But Saddam Hussein $\uparrow$

156. didn’t $\uparrow$ knock down World Trade Center $\uparrow($.$) He had nothing to do with \underline{\mathrm{it}} \uparrow$

157. And there were no weapons of mass destruction $\uparrow($.$) There was nothing \uparrow$

158. Saddam Hussein=you know what he did with the terrorist $\uparrow$ ? He killed

159. them(.) He would kill terrorists(.) And now Iraq is a breeding ground(.)

160. That's where all the terrorists are going(.) They're going to Iraq $\uparrow($.

161. because that's the safest place for them to be(.) And we're in this...

(Bold and italicized fonts in lines 153, 157 and 158 indicates the register used by the interviewee when responding to the Iraq War posed by the interviewer.)

\section{DISCUSSION}

The findings of this research showed that institutional roles affect the choices of strategies used by speakers during conversation. It is reflected in the research that most of the time, the role of interviewer: to ask; and the role of interviewee: to answer, are done successfully. Apart from that, the "flow" or adjacency pair in the interview is important to maintain the audience's attention throughout the session.

The fact that when the interviewee addressing the interviewer by name every time he answered shows that he is responding exclusively to the interviewer. Surprisingly, this situation happened when only the interviewee responds about something personal and probably wants to share the same view with the interviewer and the audience, generally. His 'soft' and 'personal' approach is an interesting approach to point out view some focal views to the overhearing audience.

The strategy to control the direction of the conversation reflects in the interviewer's action of repeating the questions. The repetition of question happens because the interviewer is expecting a predictable response from the interviewee. During the interview, the interviewer is seen as a participant who is probing interviewee's view and to ensure that the questions are answered appropriately. Thornborrow added that the interviewer also needs to ensure the agenda and the direction of the interview [10].

Interaction and overlaps can also be detected throughout the interview. Interruptions occur when the interviewer feels that the interviewee is deviating his answer away from the topic. It also happened when the interviewee refused to stop answering and commenting while the interview feels that the interviewee has made his point quit enough [10]. There is no doubt that probably the interviewee wants the audience to be convinced with his answer. However, due to time constraint and also the need to ensure that the interviewee answers the question appropriately and adequately, allow the interviewer to interrupt. These interruptions and overlaps may not be classified as mismanaging the turn-taking organization by the speaker, but more as interjecting point where a speaker immediately point out any important statement made by the interviewee.

The choices of lexical also reflect the institutional role of both interviewer and interviewee. Both of them seem to use appropriate and suitable words during the interaction. As the chairman of the multi billion Trump Group of Companies, where real estate development and investment is his specialty, the interviewee uses words that really reflects his capacity and his profession's context. By addressing himself as "we" during certain point of the interview, the interviewee is trying to portray his personal attachment to the people that work with him and for him. This is probably because he realized the importance of those people who have been the backbone of the company. It is an interesting fact that the interviewee is using "we" despite the question from the interviewer is not design specifically to trigger interviewee's organization point of view. The interviewee also uses different type of register when commenting on the Iraq War. As one of the most influential man in the United States, his choice of words portrays his hatred towards the situation in Iraq. This shows that he has successfully maintained his reputation of being multi-institutional representatives where he is able to specifically discuss the topic of "real estate" and also other issue like the Iraq War. 
The answer or comments from the interviewee are constructed in a way that is easily understood and effectively conveyed to the audience. Furthermore, the strategy of pausing after he delivers some important points enables him to emphasis on certain points that need to be adhered and at the same time allow audience to focus on the flow of ideas.

\section{CONCLUSION}

Based on the evidence gathered in this research, it is clear that institutional role does affect the type of conversational strategies in any interaction. However, it is important to note that the one who is more powerful and has greater responsibility to control the conversation is likely to holds the floor regardless of his or her institutional representation. In terms of clarity of the message, speakers need to be alert of their point's organization as it may affect the overall flow of the conversation and also the clarity of the message. Such situation is likely to allow more interruptions happened as the interviewer may likely to interject the conversation in order to obtained the condition response from the interviewee. On the other hand, audience may likely to gradually lose their attention if this problem persists throughout the interview. This problem may be overcome if only both speakers are able to regulate those strategy proposed by Heritage wisely and appropriately.

\section{References}

[1] Cheepan, C. (2000). Small talk in service dialogues: The conversational aspects of transactional telephone talk. In Small Talk. J. Coupland (ed.), 288-311. London: Longman.

[2] Duncan, S. (1973). Towards a grammar for dyadic conversation. Semiotica 9: 29-46

[3] Goodwin, C. (1981). Conversational organization: Interaction between speakers and hearers. New York: Academic Press

[4] Heritage, J. (1997). Conversation analysis and institutional talk: Analyzing data. In D. Silverman (Ed.), Qualitative research: Theory, method and practice. London: Sage Publications.

[5] Norsfinger, R. E. (1991). Everyday conversation. Newbury Park: Sage Publications.

[6] Sacks, H., Schegloff, E. A., \& Jefferson, G. (1974). A simplest systematics for the organization of turn-taking in conversation. Language. 50(4): 696-735.

[7] Sacks, H., Schegloff, E. A. \& Jefferson, G. (1978). A simplest systematics for the organization of turn-taking in conversation. In Studies in the Organisation of Conversational Interaction, J. Schenkein (ed.), 7-55. New York: Academic Press.

[8] Sacks, H. (1992). Lectures on conversation. In G. Jefferson (Ed)., Lectures on conversation (Vol.2). Massachusetts: Blackwell Publishers.

[9] Ten Have, P. (1999). Doing conversational analysis: A practical guide. London: Sage Publications.

[10] Thornborrow, J. (2002). Power talk: language and interaction in institutional discourse. London: Pearson Education limited.

[11] Tolson, A. (2006). Media talk: spoken discourse on tv and radio. Edinburgh: Edinburgh University Press.

[12] Warren, M. (2006). Features of naturalness in conversations. Philadelphia: John Benjamins Publishing Company. 